\title{
Appropriate use of antipsychotic drugs is feasible in outpatients' dementia clinics
}

\author{
Teresa Catarci* \\ Dementia clinic Casa della Salute S. Caterina della Rosa ASL Roma2, Rome, Italy
}

\begin{abstract}
The use of antipsychotic drugs in patients with dementia is not recommended due to their high mortality index and significant increase of cerebrovascular events, in fact they should be prescribed only when all the other treatments fail or when there is an obvious danger for the patient or his/her caregiver. Nevertheless, the most recent report on the use of drugs by the Italian Medicines Agency shows a constant increase of prescriptions.

We retrospectively evaluated the prescription of typical and atypical antipsychotics in 190 patients with dementia visited in a time interval of two years in our outpatients' dementia clinic.

We found that $47.9 \%$ of them reported more or less severe behavioural symptoms, although $9 \%$ only needed antipsychotic drugs. Mini Mental State Examination was assessable in seven out of 17 patients and the scores ranged from five to $23 / 30$.

Our results are in line with other larger specialist settings' reports of $6,2 \%$ and $11,4 \%$, meaning that careful management of patients with dementia and their caregivers, as it happens in dedicated outpatients' clinics, allows a limited use of antipsychotic drugs.
\end{abstract}

\section{Introduction}

Most international guidelines do not recommend the use of antipsychotic drugs in patients with dementia, due to their high mortality index and significant increase of cerebrovascular events and clearly state that behavioural treatment and counselling are the first option. Appropriate use of antipsychotics (typical and atypical) is considered only when all the other treatments fail or when there is an obvious danger for the patient or his-her caregiver $[1,2]$. These recommendations apply to both older typical antipsychotics and newer atypical ones, and, although the latter have a better tolerability profile in the elderly due to their lower extrapyramidal impact, it should be considered their negative effect on metabolism [3].

In Italy, new antipsychotics are not indicated to treat psychosis in dementia, except for risperidone for a limited amount of time (six months) and clinical guidelines clearly state that the first option to be considered is behavioural treatment and counselling [4], in order to apply strategies involving distraction and redirection, followed by or contemporary to symptomatic treatment with Acetylcholinesterase inhibitors (ACheI) and/or memantine, also taking in consideration drug switch, adjustment of dose or co-administration. Should these procedures be insufficient, then antidepressant drugs could be prescribed such as trazodone, mirtazapine or citalopram. Antipsychotics should be prescribed only when all the other treatments fail or when there is an obvious danger for the patient or his-her caregiver, where risperidone or olanzapine show the best risk/benefit ratio [4].

In Italy, it is highly possible that the management of psychosis in dementia is not currently done following such guidelines: the recent report on the use of drugs by the Italian Medicines Agency shows a constant increase of use from 2013 to 2017 [5], the same has been reported to occur in Spain [6], while the United Kingdom finally achieved a large reduction of prescriptions from $22,1 \%$ in 2005 to $11,4 \%$ by 2015 [7].

Therefore, we decided to evaluate the prescription of typical and atypical antipsychotics in our series of patients with dementia, in order to verify our compliance with treatment guidelines.

\section{Methods}

All patients had been visited in a secondary care Dementia out-patient Clinic of the Italian National Health Service in Rome. Occasionally, patients might have been followed up at home when their medical conditions were critical or in case of severe behavioural symptoms. In this kind of clinic, the staff is limited to a neurologist, a geriatrician and one part-time nurse to assist the visit; there are no neuropsychologists or social service assistants.

Data have been gathered from the notes related to drug direct distribution to the caregivers, which were later sent to the pharmacy of our outpatients' dementia clinic, from May 2014 to May 2016. They were then crosschecked with the internal drug distribution checklist and patient's clinical record files. The patients who took at least one dose of antipsychotic drugs were included in the data analysis. Because of limited time available for the analysis, it was decided to collect the data from the series of patients seen by the Neurologist (TC) only.

Behavioural symptoms were essentially reported by the caregivers of the patients and considered so if they included at least one of the

*Correspondence to: Teresa Catarci, Dementia clinic Casa della Salute S. Caterina della Rosa ASL Roma2, Rome, Italy, Tel: +39 067730 7581; E-mail: teresa.catarci@aslroma2.it

Received: September 06, 2018; Accepted: October 03, 2018; Published: October 10,2018 
following: bothersome hallucinations, aggressive behaviour or agitation. Treatment was advised following the Italian guidelines available at the time of the survey [4]. All patients and/or their caregivers gave their written informed consent to be treated with an antipsychotic drug for behavioural disturbances in dementia, the local ethical committee had been fully informed about the survey.

\section{Results}

One hundred and ninety patients had been visited in the clinic in the time interval reported above, 126 females 64 males, mean age $82.5 \pm$ 7.1 years, 87 (47.9\%) of whom were reported to have more or less severe behavioural symptoms. Seventeen patients only (9\%) were prescribed antipsychotic drugs: 11 females and 6 males, mean age $80.4 \pm 9.4$ years. Fifteen had been diagnosed possible Alzheimer's disease, one Lewy body dementia and one post-stroke dementia. Ten out of 17 patients were regularly followed-up in the clinic, while the more severe seven patients were seen at home. Mini Mental State Examination was not assessable because of severe cognitive impairment in 10 patients, the remaining 7 patients' scores ranged from 5 to 23/30. Patient's prescriptions were as follows: one risperidone, 2 clozapine, 14 quetiapine (dose ranges 25$100 \mathrm{mg}$ per day); seven patients were also prescribed memantine plus AcheI.

The remaining patients with behavioural symptoms who were not prescribed antipsychotic drugs were treated with clonazepam, trazodone and/or appropriate doses of AcheI or memantine and caregivers were given appropriate advices to manage the symptoms (like for example diversive activity). Clinical data about this set of patients have not been evaluated in this present survey.

\section{Discussion}

We performed a brief survey of our patients with dementia, in order to monitor our compliance with national and international guidelines on the treatment of behavioural symptoms, also considering the reported increase of prescription of antipsychotic drugs in Italy.

In our population of 190 patients with dementia, $9 \%$ only were prescribed antipsychotic drugs to manage their behavioural symptoms, in line with other larger specialist settings' reports of $6,2 \%$ and $11,4 \%$ [8]. About half of the patients took drugs to improve their cognition, in order to keep the dosage of antipsychotics the lower possible.

Due to limited staff resources, we could not retrieve clinical data about the whole population of patients, therefore more detailed data are reported only for the patients who were prescribed antipsychotic drugs.
Nevertheless, our data show that careful management of patients with dementia and their caregivers, as happens in dedicated outpatients' clinic (even if based in secondary care), allows a limited use of antipsychotic drugs, as also reported in other larger case series in Sweden and Spain. Moreover, the introduction of national dementia strategies in UK determined a significant decrease of prescription of antipsychotics, also due to a relevant increase of prescription of drugs to improve cognition.

Therefore, our data, in addition to those reported in the literature, support the need of specialist dementia clinics to be widely spread in the national territory, in order to reduce the indiscriminate use of the potentially hazardous antipsychotic drugs and to deliver a better quality of care for people with dementia and their caregivers.

\section{Acknowledgements}

Many thanks to the staff of S. Caterina della Rosa who helped with the data collection and allowed the use of notes and checklists.

\section{References}

1. Dementia: assessment, management and support for people living with dementia and their careers. Nice guideline. 2018. Available from: https://www.nice.org.uk/guidance/ ng97.

2. APA Steering Committee on Practice Guidelines. The American Psychiatric Association Practice Guideline on the use of Antipsychotics to Treat Agitation or Psychosis in Patients with Dementia. APA Practice guidelines 2016:1-210

3. Lieberman JA, Stroup TS, McEvoy JP, Swartz MS, Rosenheck RA, et al. (2005) Effectiveness of antipsychotic drugs in patients with chronic schizophrenia. $N$ Engl $J$ Med 353: 1209-23. [Crossref]

4. Sindrome demenza Diagnosi e Trattamento, Linee Guida Regione Toscana 2011 (updated 2015). Available from: https://www.ars.toscana.it/files/aree_intervento/ salute_di_anziani/lg_toscana_demenza_2011.pdf

5. The Medicines Utilisation Monitoring Centre. National Report on Medicines use in Italy. Year 2017. Rome: Italian Medicines Agency. Available from: http://www.aifa. gov.it/sites/default/files/Rapporto_OsMed_2017_AIFA.pdf

6. Calvó-Perxas L, Turró-Garriga $\mathrm{O}$, Aguirregomozcorta M, Bisbe J, Hernández E, López-Pousa S, et al. (2014) Psychotropic drugs in patients with Alzheimer's Disease: a longitudinal study by the Registry of Dementias of Girona (ReDeGi) in Catalonia, Spain. J Am Med Dir Assoc 15: 497-503. [Crossref]

7. Donegan K, Fox N, Black N, Livingston G, Banerjee S, Burns A (2017) Trends in diagnosis and treatment for people with dementia in the UK from 2005 to 2015: a longitudinal retrospective cohort study. Lancet Public Health 2: e149-56. [Crossref]

8. Garre-Olmo J, Garcia-Ptacek S, Calvó-Perxas L, Turró-Garriga O, López-Pousa S, Eriksdotter M (2016) Diagnosis of Dementia in the Specialist Setting: A Comparison Between the Swedish Dementia Registry (SveDem) and the Registry of Dementias of Girona (ReDeGi). J Alzheimers Dis 53: 1341-1351. [Crossref]

Copyright: (C2018 Catarci T. This is an open-access article distributed under the terms of the Creative Commons Attribution License, which permits unrestricted use, distribution, and reproduction in any medium, provided the original author and source are credited. 